\title{
INVOLVING CONSUMERS IN THE VALUE CREATION IN THE CONTEXT OF ICT DEVELOPMENT
}

\author{
Regina Virvilaite $^{1}$, Aiste Ragauskaite ${ }^{2}$ \\ ${ }^{1,2}$ Kaunas University of Technology, Lithuania \\ cross $^{\text {ref }}$ http://dx.doi.org/10.5755/j01.em.18.2.3982
}

\begin{abstract}
Analyzing different types of consumers and factors, which influence the involvement in the value creation, the process of consumers' involvement is perceived as a complex system, which the company has to control, in order to get full and active participation of consumers. The aim of the work - prepare a conceptual model of consumers involvement in the value creation in the context of ICT development.

First of all, it seeks to reveal the conceptual essence of the value in the latest marketing theories. It identifies the shared value dimensions, supported by its development theoretical approaches (Dholkia et al., 2003; Prahaland \& Ramaswamy, 2004). The paper identifies and supports the dimensions of shared value for the user; reveals features of consumers' involvement into value creation. The concept of consumers' involvement is based on identifying the factors which determine the consumers' involvement into the value creation. Based on generalized theoretical provision, it is prepared a conceptual model of consumers' involvement into the value creation in the context of ICT development.
\end{abstract}

The type of the article: Theoretical paper.

Keywords: value creation, consumers' involvement in the value creation, ICT context.

JEL Classification: L23; M30; O32.

\section{Introduction}

Traditionally, value is created in a company and directly offered to consumers. But in ICT development conditions, consumers are included to participate in various activities of the company, especially in value creation process. The optimized value creation process, which actively involves consumers, can deliver the greatest benefits for the company. Therefore, it becomes important for companies to review value creation process, evaluate the need of consumers' involvement into the value creation and to determine the benefits for both - consumers and the business. This is a new approach and a new research in consumers and business collaboration interface.

Despite social and economic transformations, both the traditional and the latest marketing theories reveal that the idea of value creation for consumers remains a relevant research object. This is supported by the marketing researchers' argument that company's success depends on its ability to provide substantial, sustainable and unique value to consumers. Although, traditionally it is claimed that the value is created in companies and is directed to consumers, the consumers are enabled to actively participate in various companies' activities based on conditions of ICT development (Solis, 2010; Marsden, 2011). In response to this, companies are forced to take a fresh look into the value creation process, which means to evaluate consumers' possibilities to be involved in the value creation, underlying assumptions for the shared value, which provides benefits to both - the consumers and the enterprises. In this context, it should be noted that the consumers' changes they/them position from passive to active and his involvement in the value creation provides additional benefits as well as increased general satisfaction with the perceived value.

In the light of the research context of value creation and incorporation of consumers, it is obvious that despite the growing interest to create and offer value to consumers, it is difficult to find solid value to consumers' conception in scientific literature. This uncertainty raises problematic 
questions such as different consumers' involvement in the understanding of the value process and the distinguishing of essential factors. In order to increase its competitive ability, the business undertakes new trends related to the context of ICT (Information and Communications Technology) development. ICT provides new opportunities and prospects to establish the connection between consumers and companies with a view to create a solid value.

A great number of researchers (Flint et. al., 2002; Smith \& Wheeler, 2002; Nagle \& Holden, 2002; Anderson \& Narus, 2004; Holbrook, 2005, etc.) have analyzed the concept and dimensions of the value to consumers, but the solid definition describing value's cause is not found in the scientific literature. It is due to the fact, that researchers mostly have different perspectives. On the other hand, not so many researchers talk about the consumers' involvement in the processes, and even when they do talk, the researchers link motivation factors with psychological alternatives (Rodie \& Kleine, 2000; Pini 2009; Hoyer et al., 2010, etc.). Analyzing ICT context it can be stated that ICT development receives more attention in a broader sense, while minimal attention is paid to the specific subject part. Social networks remain one of the components in the ICT development context, taking into account creation of effective connections between the business and the consumers. Shu and Chuang (2011) claim that scientists use the term "social network" in order to understand dynamic interpersonal changes which take place in the environment of relatives and societies. Social interaction is the key feature of social networks and it greatly affects the sharing of interpersonal knowledge (Chiu et al., 2011).

The original review of the scientific literature has revealed that the value itself and consumers' involvement are treated differently. Only a few scientists distinguish factors, which are contributing to consumers' involvement. Moreover, the current ICT situation regards consumers' involvement to the process of value creation, provides a context which also affects the process itself and the consumers' involvement. Scientific research allows us to identify problematic situations and provides an opportunity to formulate the research problem in a form of a question: which factors affect consumers' involvement in the process of value creation in ICT development context?

Scientific opinions reveal that the companies in today's business environment are motivated to work together with the consumers, because this would lead to the increased product value. If interest groups are combined to generate the value, a scientific problem arises: the involvement of consumers to create a value in ICT development context.

The aim of this research - to prepare a conceptual model of consumers' involvement in the value creation process in the context of ICT development.

\section{Consumers involvement in the value creation process of ICT development in the context of a scientific theoretical level}

Constituent factors are relevant through the process of consumers' involvement in the creation of value in ICT context. Impact on consumers' involvement to the process of value creation can be defined while analyzing scientific sources only by crystallizing the explicitness of value itself, the principles of consumers' involvement and the most important, the relationship between the consumers and the enterprises in the context of ICT (in this case social network is the only component) environment in order to clarify the factors of a process and to establish certain principles. In scientific literature the very process is not analyzed as the whole process but as individual components. However, it is important to determine their weights when connecting the components together.

Value, in this scientific case, is the key deliverable, based on the other factors. Scientists often introduce different value to consumers' conceptions. The analysis of different views allows us to determine the essential concepts of value and to monitor its dynamics' due to scientific opinions. The perception of value from the point of an enterprise and the view of consumers is aggravated by its constantly changing perception (Grönroos, 2004). As a result, different treatment requires a thorough analysis of the value itself. 
Table 1. Definitions of value to consumers

\begin{tabular}{|c|c|}
\hline Author & Value to consumers conception \\
\hline Lanning, 1998 & $\begin{array}{l}\text { If was allowed to choose, a consumers would consider it as the final consequence of } \\
\text { acquisition cost rather than the alternatives. }\end{array}$ \\
\hline Flint et al., 2002 & $\begin{array}{l}\text { User's expectations in cooperation with the manufacturer while using its product or } \\
\text { service. }\end{array}$ \\
\hline $\begin{array}{l}\text { Eggert \& Ulaga, } \\
2002\end{array}$ & $\begin{array}{l}\text { A certain combination of physical characteristics of a product or service and technical } \\
\text { support. }\end{array}$ \\
\hline $\begin{array}{l}\text { Nagle \& Holden, } \\
2002\end{array}$ & Gross savings or satisfaction of a product received by the consumers. \\
\hline $\begin{array}{l}\text { Anderson \& } \\
\text { Narus, } 2004\end{array}$ & $\begin{array}{l}\text { Assets in monetary terms, economical, technical, service and social benefits which } \\
\text { consumers receives in exchange for market bid price. }\end{array}$ \\
\hline Holbrook, 2005 & Interactive, relativistic anteriority or experience. \\
\hline
\end{tabular}

To summarize scientific research analysis, it can be concluded that the value is treated as the profit received by the consumers and which is essential for the enterprises when it provides value to the consumers together with the product. Therefore, the uncertainty of the value allows us to treat the value according to the needs of consumers and the company. In general, stakeholder groups' interface creates the value corresponding to the needs of both parties. Value to consumers' concept is related not only with the price paid by consumers, but it also highlights the wide range of returns, which are directly linked with the use of purchased item. The definitions of value to consumers emphasize three time dimensions: the concept of consumers value until the interaction with the manufacturer (consumers desires); the importance of interaction with the manufacturer (price paid by the consumers); the concept of consumers value after the interaction with the manufacturer (product's profit to the consumers).

The principles of consumers involvement cause the most scientific discussions due to subjective consumers' choice. Consumers involvement in value creation is a behavioral concept, related with the consumers' actions and resources required to create and/or deliver (Rodie \&Kleine, 2000). Consumers involvement during the creation of a product depends both on individual experience, because every person is unique, thus differently affects the creation process (Egart, 2007), and on consumers' need and perception on how to be involved the product creation (Good, 1990). According to scientists, the motivational factors for the consumers to participate in value creation process are: financial rewards, social benefits, knowledge acquisition opportunities, psychological reasons (e.g. self-expression). Higgins (2006) emphasizes that the value is a motivating force. According to Nelson (Salbin, 2004), some consumers motivating factors are: development, challenges, encouragement, appreciation (recognition), the use of advantages, learning, error tolerance, measurement, alternatives, responsibility, leadership opportunities, social interaction, group work, activity, pleasure, variety, contribution and ownership sharing. It is also important to take in consideration material factors (monetary and output rewards, etc.). Consumers as an individuals also reveals the needs, which they/them fulfills throughout the value creating process; those are physiological, safety respect, self-acceptance and self-expression factors (Maslow, 1954, Robbinson, 2003). In order to establish the optimum process, it is advisable to figure out the factors which encourage involvement the most and which encourage further scientific research. However, the preceding scientific research and the observed interface between the consumers, the companies and the value creation are loaded in the context of ICT development.

While analyzing the latest scientific resources, value creation is transferred to virtual space on the ground of the value creation a technologically friendly environment for all stakeholders. 
Appealing to additional scientific research Shu and Chuang (2011) offer different consumers' views and motives to join social networks which also emphasize community principle - meeting new people, entertainment, keeping in touch, understanding, participating in social life, confidence in websites and other members. While involving consumers' communities, it is likely to collect more information and achieve higher generated value.

The integration of suppliers, manufacturers and other stakeholders and components in value creation using the latest economy, through information and communications' technologies, suggests presumption that such managerial decision will help the business survive and generate bigger revenue (Kohli \& Melville, 2009). Active consumers' actions' transfer to virtual space encourages enterprises to move their activities also there. It is statistically stated that social networks - in this case out of overall ICT development context - create the most favorable connection and environment for joint processes of consumers and enterprises. According to Di Gangi et al. (2009), information communication technologies provide consumers the opportunity to engage in innovative value creation while using the latest technologies. As the result of overall process we have an environment that influences the value creation process and consumers involvement factors. The latest technologies (computer, telephone, video calls, internet possibilities, portals, forums, websites, communication environment, etc.) and each factor differently affect the consumers' involvement in value creation process in the context of ICT development.

\section{Consumers' value creation in the ICT development in the context of a theoretical solution}

Conceptual model on the consumers' involvement to value creation in ICT development context was created according to research and scientific findings.

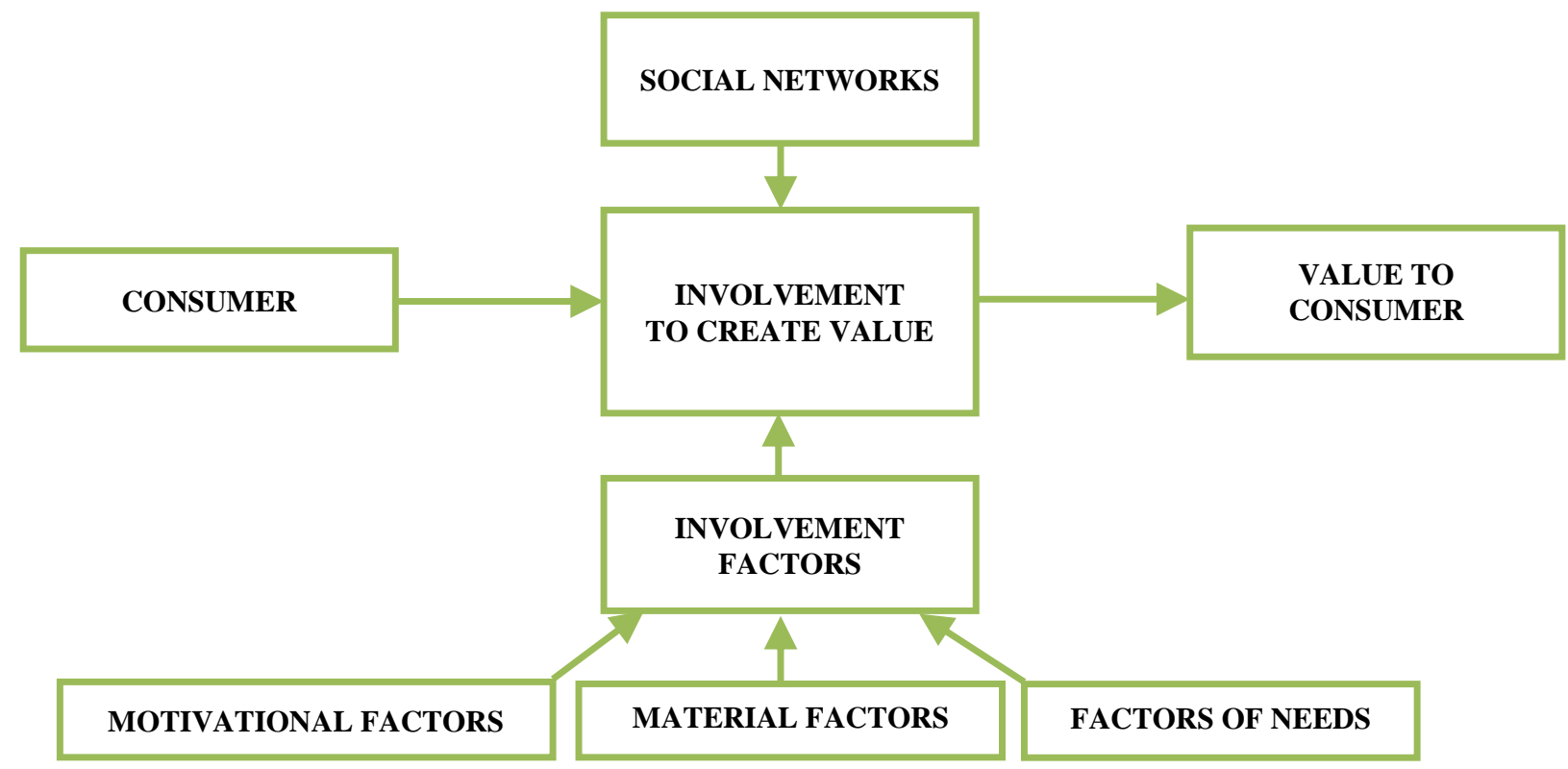

Figure 1. Conceptual model on consumers' involvement in the creation of value in ICT context (designed by the author)

When summarizing the results of many scientific works and research, analyzing each value and consumers' involvement separately, and the context of Information and Communications technologies (ICT), allows distinguishing the essential factors:

Motivational factors. According to Zwass (2010) there is a number of motivators in order to involve consumers in the process of development: altruistic desire to contribute, passion, inner need to reciprocate, enjoyment, state of flow, playfulness, self-expression, identity construction, forming personal relationships, community norms, competitive spirit, learning, satisfying one's affiliation 
needs, self-esteem and self-efficacy, acquiring social capital and peer recognition, career advancement, own use, non-monetary rewards. These identified motivators are supplemented by Roser (2009): image, status, own ideas demonstration, interest, learning, pleasure, helping the others and being part of the group. Nelson (op. cit. Salbin, 2004) identifies the greatest number of motivators and adds more to the list conducted by previous researchers: advancement, challenges, encouragement, evaluation (validation), activity, pleasure, variety, contribution, significance, the use of advantages, learning, error tolerance, goals, alternatives, responsibility, leadership opportunities, social interaction, and teamwork. In order to summarize the factors, it can be stated that every scientist identifies different factors, but several of them are mutually selected and this shows a tendency between generalized factors which are likely to have a greater impact than nonrepetitive ones.

Financial factors. Zwass (2010) also identifies financial rewards. Roser (2009) names more specific financial rewards: money, goods, tested production, gifts, etc.

Needs factors. Reiss (2004) identifies 16 essential human needs which stimulate us act and pursue satisfaction: power, curiosity, independence, status, social interaction, revenge, honor, idealism, physical education, romance, family, organizing, eating, acceptance, tranquility, and economy. Nevertheless, Maslow (1954) introduced fundamental needs and needs' systematization. He identified: the need of self-expression, the need of self-recognition, the need of respect, social needs, the need of safety, and physiological needs. Meanwhile Robinnson (2003) explicitly explains the needs by Maslow and distinguishes:

- Physiological needs. Connected to human physiology: the need hear, hunger, thirst, etc.

- The need of safety. Human being tries to protect himself/herself from physical and emotional damage. For example, he/she is not willing to reveal personal information in virtual environment, because strangers might find it out.

- Social needs. Building a relationship with other people, friendship, networking, the sense of responsibility, communication, etc.

- The need of respect. From the point of internal factors: independence and luck. However, there are external factors such as status, recognition, attention and the desire to belong in a group.

- The need of self-recognition. Internal desire of consumers is linked with self-assessment. It can be high or low, this will lead to consumers' confidence in they/them actions and opinion.

- The need of self-expression. This need expresses the own 'I' of a personality. The aim is to develop own advantage among other individuals, to improve and to increase competitive advantage.

To summarize the needs, identified by several scientists, it can be stated that the most relevant needs - when involving consumers to the process of value creation in ICT development context - are social needs and the needs related to self-evaluation.

Consumers. Traditionally consumers were considered only as the value receiver, and the value was created and suggested by the manufacturers. The new approach suggests that consumers become co-creators and from passive value creators develops to an active one (Dong, 2007; Prahalad \& Ramaswamy, 2004, etc.)

Involvement Process. According to scientists, consumers' motivation, motivational factors and the benefits of involvement are the most important during the process of involvement. In order to convey a smooth involvement, the framework of value creation must be clear, the tasks must be formulated and the manufacturer's objective must be explicit (Kotler et al., 2003; Higgins, 2006). Scientists (Hoyer, et al., 2010; Rodie \& Kleine, 2000; Prahalad et al., 2004, etc.) distinguish the essential factors: motivational factors (development, challenges, encouragement, appreciation, recognition, etc.), material factors (money, reward, production, etc.), factors of demands (social recognition, physiological and etc.).

Social Networks. It is a new, unexplored space, which offers a number of tools to communicate with consumers and to create a friendly environment for cooperation. Social networks 
grant with opportunities to implement a new process to create value, while effectively reducing time and expense costs and involving as many consumers as possible (Dahan \& Srinivasan, 2000; Morgan et al., 2000; Nambisan, 2002; Weber, 2009, and etc.). When analyzing the newest scientific sources, value creation is transferred to virtual space as it creates a friendly environment for value creation for all stakeholders.

Solid value. Scientists have a different approach to value and such multiplicity requires deeper exploration of value itself. In most cases we view value from the perspective of consumers: what value receives consumers when they/them purchases the product. However, the manufacturer encounters a challenge to create a value to consumers so that it would satisfy all consumers' needs and expectations. The co-creation of value allows to discover a connection between the consumers and the product, between the consumers and the manufacturer, manufacturer has no other choice, but listen to consumers' suggestions (Lusch \& Vargo 2006; Payne, Storbacka, Frow 2008; Smith \& Colgate, 2007; Grönroos, 2000, etc.). Conceptual model on consumers' involvement in the context of ICT development allows us to see interdependent processes and the factors affecting the process. In order to maximize the result, we need planning, process management, and the most important, consumers' involvement of suggested factors when creating the value (i. e. motivational, material and factors of demand). The factor of social networks enables us to determine the space parameters, the space which will be used to involve the consumers.

\section{Conclusions}

The analysis of scientific literature has allowed me to identify procedural features of consumers' involvement in value creation in the context of ICT development and to make certain conclusions.

To summarize the consumers' dimensions identified by scientists, one can assume that scientists do not comply with the consensus of opinion in the view of value definition. Researchers mainly identify three dimensions: functional, social and emotional. Given the diversity of dimensions, the peculiarities of consumers' involvement in value creation are explicitly analyzed and require further scientific research. Meanwhile, in conclusion to the results of scientific research, it is concluded that the value to the consumers might be subjective, individualized and having a great final factor in regard to acquired goods.

Consumers involvement in the context of ICT development is a new beginning in the process of product value creation. Taking over the previous experience when consumers used to be only a buyer of goods, now we are moving to a new concept where the consumers are wise, active, wellinformed and accessible anytime and anywhere. This provides new product creation opportunities and, nevertheless, an interaction between manufacturer and consumers - it generates highly additional value.

According to Surakka et al., (2010) nowadays ICT has a significant impact on the whole society, but notably on individual consumers behavior. Scientists are generating a theory that ICT development can reflect the changes of consumers' behavior and lives. According to Kohlet et al., (2011) it is possible to create a more sustainable relationship between consumers and companies in virtual environment in order to create the value. However, the process of value co-creation in virtual environment raises a number of discussions and there is no settled successfully operating model. A detailed theoretical justification reveals the need of further theoretical and empirical research.

\section{References}

Anderson, J. C., Narus, J. A. (2004). Business Market Management: Understanding, Crating, and Delivering Value (2 ed.). New Jersey: Pearson Prentice Hall.

Chiu, C., Wang, E., Shih, F. \& Fan, Y. (2011). Understanding knowledge sharing in virtual communities: an integration of expectancy disconfirmation and justice theories. Online Information Review, 35 (1), p.134- 153 . 
Dholakia, U. M., Bagozzi, R. P. (2003). Motivational antecedents, constituents and consequents of virtual community identity. In S. Godar, \& S. Pixie-Ferris (Eds.). Virtual and collaborative teams: Process, technologies, and practice (pp. 252 - 267). London7 IDEA Group.

Egart, M. (2007). A descriptive model of the consumer co-production process. Journal of the academy of marketing science, Vol. 36, No. 1., 97-108.

Flint, D. J., Woodruff, R. B., Fisher, G. S. (2002). Exploring the phenomenon of customers' desired value change in a business-to-business context. Journal of Marketing, 66.

Grönroos, Ch., (2000). Service Management and Marketing: A Customer Relationship Approach (2 ed.). Chichester: John Wiley \& Sons Ltd.

Grönroos, Ch. (2004). The relationship marketing process: communication, interaction, dialogue, value. Journal of Business \& Industrial Marketing, Vol. 19, No. 2.

Higgins, E. T., Scholer, A. A. (2009). Engaging the consumer: The science and art of the value creation process. Journal of Consumer Psychology 19, p. 100-144

Hoyer, W., Chandy, R., Dorotic, M., Krafft, M. \& Singh, S. (2010). Consumer Cocreation in New Product Development. Journal of Service Research August, p. 247-252.

Holbrook, M. B. (2005). Customer value and autoethnography: Subjective personal introspection and the meanings of a photograph collection. Journal of Business Research, 58.

Kohli, R., Melville, N. (2009). Learning to build and IT innovation platform. Communications of the ACM. 52(8), 122-126.

Lusch, R. F., Vargo, S. R. (2006). Service-Dominant Logic: Reactions, Reflections, and Refinements. Marketing Theory. 6 (3), 281-288.

Nagle, T. T., Holden, R. K. (2002). The Strategy and Tactics of Pricing. New Jersey: Prentice Hall Marketing Series.

Prahalad, C. K., Ramaswamy, V. (2004). Co-creating unique value with customers. Strategy and Leadership // Vol. 32, No. 3.

Pini, F. M. (2009). The Role of Customers in Interactive Co-Creation Practices: The Italian Scenario. Knowledge, Technology \& Policy 22 (1), p. 61-69.

Rodie, A. R., \& Kleine, S. S. (2000). Customer Participation in Services Production and Delivery. In T. A. Swartz, \& D. Iacobucci (Eds.). Handbook of Services Marketing and Management: 111-125. Thousand Oaks: Sage Publications.

Salbin, B. F. (2004). Recognition motivates employees to excel Health Care Registration: The Newsletter for Health Care Registration Professionals. Vol. 13 (6), p. 3-5

Shu, W., Chuang, Y. (2011). The perceived benefits of six-degree-separation social networks. Internet Research, 21 (1), p.26-45.

Smith, J. B., Colgate, M. (2007). Customer Value Creation: A Practical Framework. Journal of Marketing Theory and Practice. Vol. 15, No. 1.

Smith, S., Wheeler, J. (2002). Managing the Customer Experience. London: FT Prentice-Hall.

Urban, G., Hauser, J. R. (2004). Listening in" to find and explore new combinations of customer needs. Journal of Marketing 68 (April), 72-87. 